\title{
Crescimento de plantas de cobertura sob déficit hídrico
}

\section{Cover crops growth under water deficit}

\author{
Edison Ulisses Ramos Junior ${ }^{1 *}$; Rogério Alessandro Faria Machado²; \\ Dácio Olibone ${ }^{3}$; Gustavo Castoldi ${ }^{4}$; Beatriz Meneguce Ramos ${ }^{5}$
}

\begin{abstract}
Resumo
Um dos desafios a serem vencidos na implantação do sistema de semeadura direta em regiões tropicais é a produção de palhada na entressafra, período comumente com baixa disponibilidade hídrica. Visando auxiliar a escolha das espécies a serem empregadas como planta de cobertura em regiões de inverno seco, objetivou-se com este trabalho avaliar o efeito de potenciais de água no solo no crescimento de aveia preta (Avena strigosa Sckreb), milheto (Pennisetum glaucum (L.) R. Brown), sorgo granífero (Sorghum bicolor L. Moench.) e sorgo-de-guiné (Sorghum bicolor subespécie bicolor raça guinea). O milheto, mesmo sendo mais sensível ao déficit hídrico, mostrou-se uma boa opção a ser cultivado na entressafra pelo seu elevado potencial produtivo. O sorgo granífero e o sorgo-de-guiné também são boas opções, em especial por terem apresentado abundante sistema radicular, o que possivelmente conferiu aos mesmos certa tolerância a condições de baixa disponibilidade hídrica. A aveia preta, mesmo apresentando aparentemente elevada tolerância à deficiência hídrica (tolerância esta conferida pela maior porcentagem de raízes finas), parece ser muito prejudicada por temperaturas mais elevadas, comuns a estas regiões.

Palavras-chave: Matéria seca, raiz, aveia preta, milheto, sorgo granífero, sorgo-de-guiné
\end{abstract}

\begin{abstract}
One of the challenges to be overcome in no till deploying in tropical regions is the production of straw in the offseason, a period commonly with low water availability. To help in the choice of species to be used as cover crop in dry winter regions, the aim of this work was to evaluate the effect of soil water potential on growth of black oat (Avena strigosa Sckreb), pearl millet (Pennisetum glaucum (L.) R. Brown), grain sorghum (Sorghum bicolor L. Moench.) e guinea sorghum (Sorghum bicolor subespécie bicolor raça guinea). Pearl millet is a good option to be cropped during offseason by show high yield potencial, even been more sensitive to water deficit. Grain sorghum and guinea sorghum are also good options, particularly by showed abundant root system, which possibly gives them a certain tolerance to low water availability conditions. The black oat, even with high tolerance to water stress (tolerance conferred by highest percentage of fine roots), seems to be much affected by higher temperatures, common to these regions.
\end{abstract}

Key words: Dry matter, root, black oat, pearl millet, grain sorghum, guinea sorghum

\footnotetext{
${ }^{1}$ Pesquisador, Dr. em Agronomia da Empresa Brasileira de Pesquisa Agropecuária, Embrapa Soja. Sinop, MT. E-mail: edison. ramos@embrapa.br

${ }^{2}$ Prof. Dr. em Agronomia da Universidade Federal de Mato Grosso, Sinop, MT. E-mail: rogymachado@yahoo.com.br

${ }^{3}$ Prof. Dr. em Agronomia do Instituto Federal de Educação, Ciência e Tecnologia de Mato Grosso, Sorriso-MT, E-mail: dacio. olibone@srs.ifmt.edu.br

${ }^{4}$ Discente de Doutorado Faculdade de Ciências Agronômicas, Dept ${ }^{\circ}$ de Produção Vegetal, Botucatu, SP. E-mail: castoldi@fca. unesp.br

${ }^{5}$ Professora Msc. em Agronomia da Faculdade Centro Matogrossense, Sorriso, MT. E-mail: bmeneguce@hotmail.com

* Autor para correspondência
} 


\section{Introdução}

Um dos desafios a serem vencidos na implantação do sistema de semeadura direta em regiões tropicais, onde a ocorrência de invernos secos é uma constante, é a obtenção de plantas adaptadas a estas condições, capazes de produzir suficiente quantidade de cobertura vegetal na estação seca e que possam ser empregadas em sistemas de rotação de culturas. A deficiência hídrica provoca alterações no comportamento vegetal cuja irreversibilidade vai depender de sua duração e severidade e do genótipo e estádio de desenvolvimento da planta (SANTOS; CARLESSO, 1998).

O sorgo granífero (Sorghum bicolor L. Moench) é uma boa opção para o cultivo na entressafra em regiões com inverno seco, especialmente pela adaptabilidade à condições de deficiência hídrica, tolerância à estiagens moderadas e elevada produção de matéria seca e ciclagem de nutrientes (MAGALHÃES; DURAES; SCHAFFERT, 2000; PORTUGAL et al., 2003). O requerimento de água relativamente baixo pelo sorgo granífero se deve à sua capacidade de permanecer em estado latente durante períodos de déficit hídrico e retomar seu crescimento em condições favoráveis (PAUL, 1990). De igual modo, o sorgo-de-guiné (Sorghum bicolor subespécie bicolor raça guinea) tem se destacado como promissora espécie a ser incorporada em sistemas de rotação de culturas em regiões de inverno seco (MATEUS; CRUSCIOL; NEGRISOLI, 2004), especialmente pela alta produção de matéria seca e ciclagem de N, P e K (MATEUS et al., 2011).

O milheto (Pennisetum glaucum (L.) R. Brown) por sua vez é uma das melhores espécies a ser cultivada na entressafra em sistemas de semeadura direta. Tal fato se deve em grande parte ao alto acúmulo de matéria seca e macronutrientes e ao baixo custo das sementes (ROSOLEM; PACE; CRUSCIOL, 2004; CRUSCIOL; SORATTO, 2009; NOZAKI; VENDRÚSCULO, 2010). O milheto pode ainda apresentar certa tolerância a seca, como resultado de um sistema radicular bem desenvolvido, que se correlaciona positivamente com a produção de grãos (JOSHI, 1987). A aveia preta (Avena strigosa Schreb.) é outra planta de cobertura capaz de produzir elevadas quantidades de palhada, auxiliar no controle da erosão e do escoamento superficial do solo e melhorar a ciclagem de nutrientes no sistema (BAYER; MIELNICZUK, 1997; DEBARBA; AMADO, 1997). Todavia o cultivo da aveia preta, seja solteira ou em consórcio com outras plantas de cobertura, é mais comum na região Sul do Brasil (PÖTKER; ROMAN, 1994; CASTOLDI et al., 2011), onde na maioria das vezes a disponibilidade hídrica não é fator limitante.

Todas as espécies acima citadas apresentam características que as fazem boas opções para o fornecimento de palhada ao sistema de semeadura direta. Entretanto, são escassos os trabalhos que avaliem tais espécies em uma mesma condição, em especial sob condições de deficiência hídrica, comuns em regiões tropicais. Visando auxiliar a escolha das espécies a serem empregadas como planta de cobertura em regiões de inverno seco, objetivou-se com este trabalho avaliar o efeito de potenciais de água no solo no crescimento de aveia preta (Avena strigosa Sckreb), milheto (Pennisetum glaucum (L.) R. Brown), sorgo granífero (Sorghum bicolor L. Moench.) e sorgo-de-guiné (Sorghum bicolor subespécie bicolor raça guinea).

\section{Material e Métodos}

O estudo foi realizado em casa de vegetação no Departamento de Produção Vegetal da Faculdade de Ciências Agronômicas, em Botucatu - SP. Durante o período experimental, a temperatura na casa de vegetação foi de $23 \pm 2{ }^{\circ} \mathrm{C}$. Foram utilizados vasos plásticos de $8 \mathrm{~L}$, preenchidos com solo da camada superficial $(0-0,20 \mathrm{~m})$ de um Latossolo Vermelho distroférrico (SANTOS et al., 2006), peneirado em malha de $4 \mathrm{~mm}$. A análise química do solo, realizada de acordo com metodologia proposta por Raij e Quagio (1983), mostrou os seguintes valores: 
pH em $\mathrm{CaCl}_{2} 4,4 ; 18 \mathrm{~g} \mathrm{dm}^{-3}$ M.O.; $14 \mathrm{~g} \mathrm{dm}^{-3} \mathrm{P}_{\text {resina; }}$; 43, 0,50, 8,0 e 4,0 $\mathrm{mmol}_{\mathrm{c}} \mathrm{dm}^{-3} \mathrm{de} \mathrm{H}+\mathrm{Al}, \mathrm{K}, \mathrm{Ca}$ e $\mathrm{Mg}$, respectivamente, e saturação por bases de $23 \%$.

Uma amostra deformada do solo foi acondicionada em anéis volumétricos de $100 \mathrm{~cm}^{3}$ para determinação da retenção de água nas tensões de $-0,3,-1,0$ e -15,0 atm, empregando-se o método das câmaras de pressão de Richards (EMBRAPA, 1997). A necessidade de calagem foi calculada de acordo com Raij et al. (1997), objetivando-se elevar a saturação por bases a $60 \%$. Após a incorporação do calcário o solo foi umedecido a $80 \%$ da capacidade de campo, sendo mantido nesta umidade por vinte dias. Juntamente com o calcário, foram incorporados $50 \mathrm{mg} \mathrm{dm}^{-3} \mathrm{~N}, 200 \mathrm{mg} \mathrm{dm}^{-3} \mathrm{P}$ e $150 \mathrm{mg} \mathrm{dm}^{-3} \mathrm{~K}$, nas formas de uréia, superfosfato simples e cloreto de potássio, respectivamente.

O delineamento experimental foi o de blocos casualizados em esquema fatorial $4 \times 3$, com quatro repetições. Foram avaliadas 4 espécies de gramíneas (Avena strigosa Sckreb, Pennisetum glaucum (L.) R. Brown cv. ADR 300, Sorghum bicolor L. Moench. e Sorghum bicolor subespécie bicolor raça guinea) e 3 potenciais de água no solo: $-0,3 \mathrm{~atm}$ (capacidade de campo), -1,0 atm (déficit hídrico inicial) e -15,0 atm (ponto de murcha permanente). O valor aproximado de potencial de água letal $\left(\Psi_{\mathrm{a}, 1}\right)$ para o milheto (Pennisetum glaucum) é de $-3 \mathrm{~atm}$ (PIMENTEL, 2004) e para o sorgo granífero (Sorghum bicolor) é de-3,5 atm (BOYER, 1978, citado por PIMENTEL, 2004). Entretanto, os potenciais utilizados neste estudo foram escolhidos justamente para comparar com o desenvolvimento da espécie em condições extremas de disponibilidade hídrica. Foram semeadas dez sementes por vaso, sendo deixadas seis plântulas por ocasião do desbaste, quinze dias após a emergência. Aos 25 dias após a emergência efetuou-se a adubação de cobertura, aplicando-se 50 mg $\mathrm{N} \mathrm{dm}^{-3}$ (uréia) e $50 \mathrm{mg} \mathrm{K} \mathrm{dm}^{-3}(\mathrm{KCl})$ na forma de solução.

O solo de todos os tratamentos foi mantido com umidade próxima à capacidade de campo (-0,3 atm) até quinze dias após a emergência das plantas. Os três potencias hídricos foram impostos a partir desta data e assim permaneceram até o final do experimento. $\mathrm{O}$ teor de água no solo foi controlado pela pesagem diária dos vasos e reposição da quantidade de água perdida. A fim de refinar o manejo da irrigação e consequente controle da água no solo, foram conduzidos vasos extras com plantas de milheto, aveia preta, sorgo granífero e sorgo-deguiné em diferentes estádios.

Cinqüenta dias após a emergência as plantas foram cortadas e lavadas em água corrente. As raízes foram separadas do solo e lavadas em água corrente sobre peneira de $0,5 \mathrm{~mm}$. A seguir foram determinadas área foliar, massa de matéria seca da parte aérea e das raízes, área foliar especifica, diâmetro médio e comprimento total radicular e o comprimento específico de raízes.

A área foliar foi obtida empregando-se um integrador de área foliar, sendo amostradas todas as folhas de cada parcela experimental. A massa de matéria seca da parte aérea e das raízes foi obtida por pesagem após secagem em estufa à $65^{\circ} \mathrm{C}$. $\mathrm{O}$ comprimento total e o diâmetro médio das raízes foram determinados a partir de sub-amostras acondicionadas em recipientes contendo álcool etílico 30\%. Estas amostras foram escaneadas e as imagens analisadas pelo software WinRHIZOä. Essas sub-amostras foram, em seguida, secas em estufa e pesadas para serem reintegradas à massa de matéria seca total das raízes. A área foliar específica foi calculada através da divisão da área foliar $\left(\mathrm{cm}^{2}\right)$ pela massa de matéria seca da parte área (g). O comprimento específico de raízes foi determinado pela divisão do comprimento total de raízes $(\mathrm{cm})$ pela matéria seca total de raízes $(\mathrm{g})$.

Os resultados foram submetidos à análise de variância e, quando detectados efeitos significativos, as médias comparadas pelo teste de Tukey ao nível de $5 \%$ de probabilidade, utilizando-se o software SISVAR. 


\section{Resultados e Discussão}

A aveia preta, o sorgo granífero e o sorgo-deguiné não tiveram a produção de matéria seca de parte aérea afetada pela disponibilidade de água no solo (Figura 1a). A tolerância ao déficit hídrico de plântulas de aveia preta já foi constatada por Liljenberg, Karunen e Ekman (1985). O sorgo granífero por sua vez apresenta alta tolerância a condições de déficit hídrico e tal característica parece estar associada a um sistema radicular bem desenvolvido (WONG, 1996), a uma redução da taxa de crescimento e controle mais efetivo da transpiração (AVELAR; MORAIS, 1986) e até mesmo à sua capacidade de permanecer em estado latente durante períodos de estresse hídrico e retomar seu crescimento quando em condições favoráveis (PAUL, 1990).

Distintamente, o milheto foi severamente afetado pela redução na disponibilidade de água (Figura 1a) e apresentou reduções na produção de matéria seca de parte aérea da ordem de 37 e $39 \%$, na ocorrência de potenciais hídricos de $-1,0$ atm e $-15,0$ atm, respectivamente. Alguns autores colocam o milheto como uma espécie que possui grande tolerância à seca (JOSHI, 1987; SKERMAN; RIVEROS, 1992), muito eficiente no uso da água (LIRA, 1983) e que apresenta melhor recuperação de um período de estresse hídrico do que o próprio sorgo granífero (PONTES, 1997), que não foi afetado pelo estresse hídrico neste estudo. Por outro lado, Lemos et al. (2003) constataram que o milheto semeado na entressafra em região de inverno seco tem seu ciclo e sua produção de matéria seca reduzidos quando da ocorrência de períodos de estiagem. Maiores foram os danos da estiagem quando esta ocorreu no estádio inicial de crescimento vegetativo, remetendo à sensibilidade hídrica do milheto neste estádio, observada também por Seiffert e Barreto (1977).
Em condições de adequado suprimento de água, condições estas que podem ocorrer esporadicamente em regiões de inverno seco, o cultivo do milheto - a fim de fornecer cobertura vegetal ao solo - mostrouse melhor opção do que o cultivo das demais espécies estudadas (Figura 1a). Por outro lado, foi muito afetado pela redução do suprimento de água. Entretanto, mesmo nos menores potenciais de água no solo, a produção de matéria seca de parte aérea do milheto assemelhou-se às das demais espécies (Figura 1a), fazendo do seu cultivo uma boa opção também em condições de estresse hídrico.

A aveia preta foi a única espécie que não teve sua área foliar afetada pelos potenciais de água no solo (Figura 1b). Tal resultado, entretanto, não significa necessariamente que a aveia preta não foi prejudicada pela redução da disponibilidade de água. Este resultado pode simplesmente ter acontecido pelo fato da aveia preta ter apresentado baixa área foliar em todos potenciais hídricos testados. Uma vez que não houve qualquer efeito da disponibilidade de água no solo, a reduzida área foliar (Figura 1b) da aveia preta ocorreu em decorrência de outro fator, muito provavelmente a temperatura do ar. A temperatura é de grande importância durante o período de perfilhamento, no qual a velocidade de crescimento das folhas depende, sobretudo, de baixas temperaturas (BELLIDO, 1990). A aveia preta é uma planta tipicamente de regiões temperadas e subtropicais, (DERPSCH; CALEGARI, 1992), onde as temperaturas na época de semeadura (março a julho) normalmente ficam abaixo dos $20{ }^{\circ} \mathrm{C}$ (FLARESSO; GROSS; ALMEIDA, 2001), de modo que as temperaturas registradas na casa de vegetação durante o período experimental podem ter prejudicado o crescimento da mesma. 
Figura 1. Massa de matéria seca de parte aérea, área foliar e área foliar específica de aveia preta, milheto, sorgo granífero e sorgo-de-guiné sob potenciais de água no solo de - $0,3,-1,0$ e -15,0 atm. Botucatu - SP.
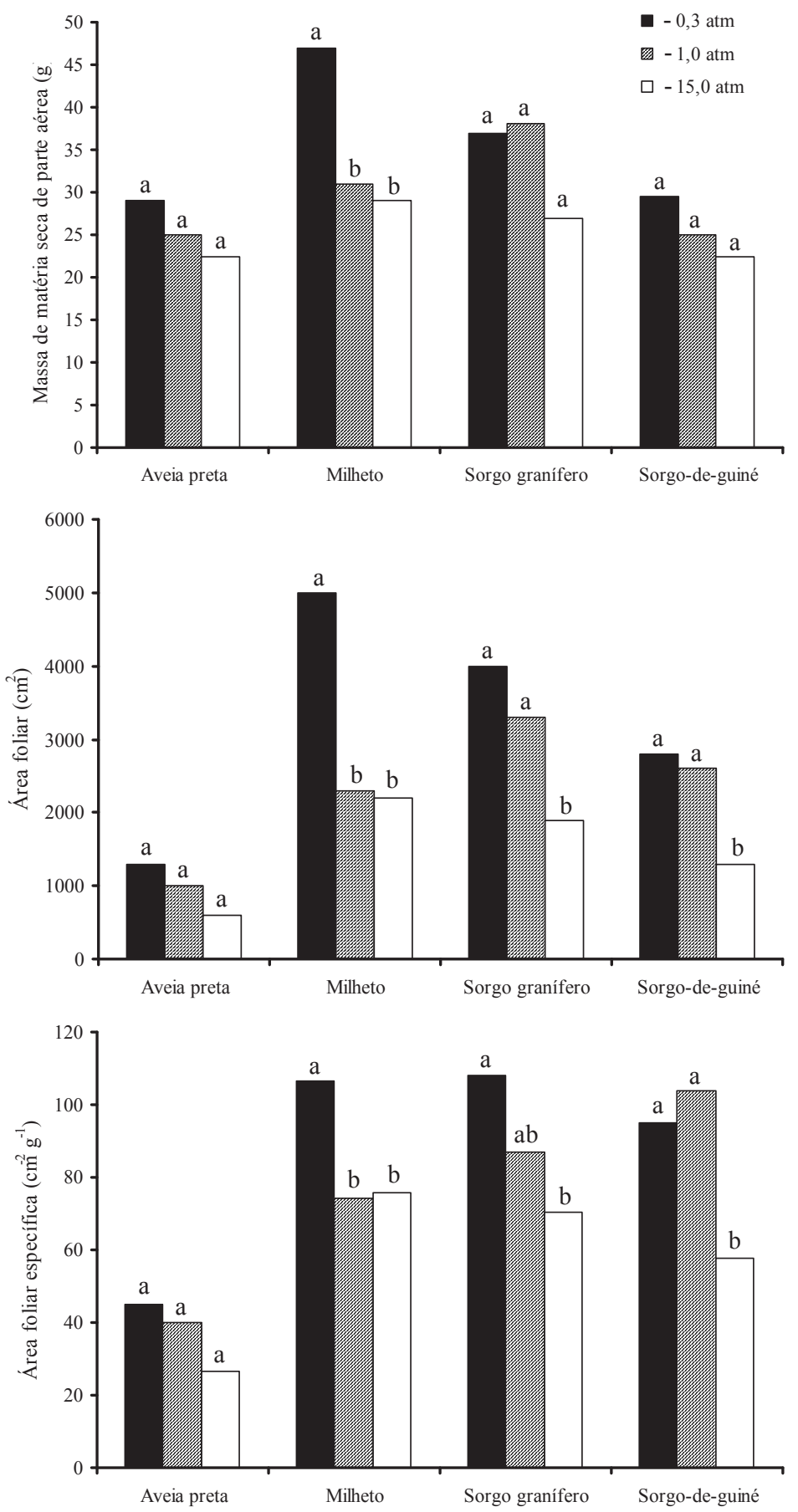

Fonte: Elaboração dos autores. 
A variação da área foliar do milheto (Figura 1b) assemelhou-se à variação da sua matéria seca de parte aérea, de modo que reduziu drasticamente nos potenciais hídricos de $-1,0 \mathrm{~atm}$ e $-15,0 \mathrm{~atm}$. O sorgo granífero e o sorgo-de-guiné apresentaram redução da área foliar somente quando cultivados no solo com potencial hídrico de -15,0 atm (Figura 1b).

Aárea foliar é um importante fator que determina a produtividade das plantas e o uso de água pelas mesmas, sendo severamente afetada por condições de déficit hídrico (FERNÁNDEZ; McINNES; COTHREN, 1996). A redução da área foliar está associada, usualmente, ao desenvolvimento foliar das plantas em situações de déficit hídrico (SANTOS; CARLESSO, 1998), sendo dentre outras coisas, a resposta mais proeminente das plantas à baixa disponibilidade de água (McCREE; FERNÁNDEZ, 1989). De modo geral, a redução da área foliar é consequencia da baixa disponibilidade hídrica e ao mesmo tempo mecanismo de tolerância à deficiência de água. Quando as plantas são expostas a situações de déficit hídrico exibem, freqüentemente, respostas fisiológicas que resultam de modo indireto, na conservação da água no solo, como se estivessem economizando para períodos posteriores (McCREE; FERNÁNDEZ, 1989).

A área foliar específica, que expressa a razão entre a área foliar e a massa de matéria seca da parte aérea, apresentou comportamento similar à área foliar para todas as espécies (Figura 1c), de modo que os maiores valores foram obtidos para o milheto, o sorgo granífero e o sorgo-de-guiné. Do mesmo modo, o milheto apresentou redução da área foliar específica quando em condição de déficit hídrico, enquanto o sorgo granífero e o sorgo-deguiné mantiveram inalterada a área foliar específica ainda que cultivados em solo com potencial hídrico de $-1,0$ atm (Figura 1c). Por descrever a alocação da biomassa da folha por unidade de área, a área foliar específica reflete a dinâmica entre a velocidade de produção de biomassa e a eficiência na conservação de nutrientes (POORTER; GARNIER, 1999). No Cerrado, a área foliar específica está fortemente correlacionada com a capacidade de fixação de carbono (FRANCO et al., 2005) e com o ponto de perda de turgor das folhas (BUCCI et al., 2004), sendo um importante parâmetro de relações hídricas.

Ao contrário da massa de matéria seca das raízes do milheto (que reduziu drasticamente quando da ocorrência de potenciais de água no solo de $-1,0$ atm e $-15,0 \mathrm{~atm})$, a massa de matéria seca radicular da aveia preta não foi afetada pela redução do teor de água disponível no solo (Figura 2a). Quanto maior o sistema radicular das plantas, maior é a tolerância das mesmas a condições de estresse hídrico (HOOGENBOOM; HUCK; PETERSON, 1987). O milheto é caracterizado por apresentar um profundo sistema radicular (JOSHI, 1987), mesmo em condições de solo compactado (GONÇALVES et al., 2006). Entretanto, no presente estudo destacaram-se o sorgo granífero e principalmente o sorgo-de-guiné, que além de ter apresentado um sistema radicular bem desenvolvido, não foi afetado pela redução da disponibilidade de água (Figura 2a). A tolerância do sorgo granífero a condições de baixa disponibilidade de água, quando comparado ao milho e milheto, também foi constatada por Singh e Singh (1995) e Nour e Weibel (1978) que verificaram que, de fato, uma das principais características de cultivares de sorgo tolerantes à seca é o maior volume radicular.

Outra característica importante e que confere às plantas maior tolerância a déficit hídricos é o comprimento específico das raízes. De modo geral, o comprimento específico das raízes de todas as espécies estudadas aumentou à medida que o potencial de água no solo diminuiu (Figura 2b). De acordo com Hoogenboom, Huck e Peterson (1987), em condições de déficit hídrico há maior expansão das raízes devido ao secamento do solo.

Ressalta-se, entretanto, o comprimento específico das raízes de aveia preta (Figura 2b). Proporcionalmente, a aveia preta apresentou mais raízes finas que milheto, sorgo granífero e sorgode-guiné. Raízes mais finas são mais eficientes em 
absorver água e conferem à planta maior tolerância a situações de estresse, o que pode explicar o fato da aveia preta não ter a produção de matéria seca, tanto da parte aérea (Figura 1a) quanto das raízes (Figura 2a), afetada pela disponibilidade de água no solo. Isso acontece porque o volume de solo explorado e o contato íntimo entre a superfície das raízes e o solo são essenciais para a absorção efetiva da água pelas raízes, de modo que o contato é maximizado pela emissão dos pelos radiculares, com conseqüente aumento da área superficial e capacidade de absorção de água (SANTOS; CARLESSO, 1998).

Figura 2. Massa de matéria seca de raízes e comprimento específico de raízes de aveia preta, milheto, sorgo granífero e sorgo-de-guiné sob potenciais de água no solo de $-0,3,-1,0$ e $-15,0$ atm. Botucatu - SP.
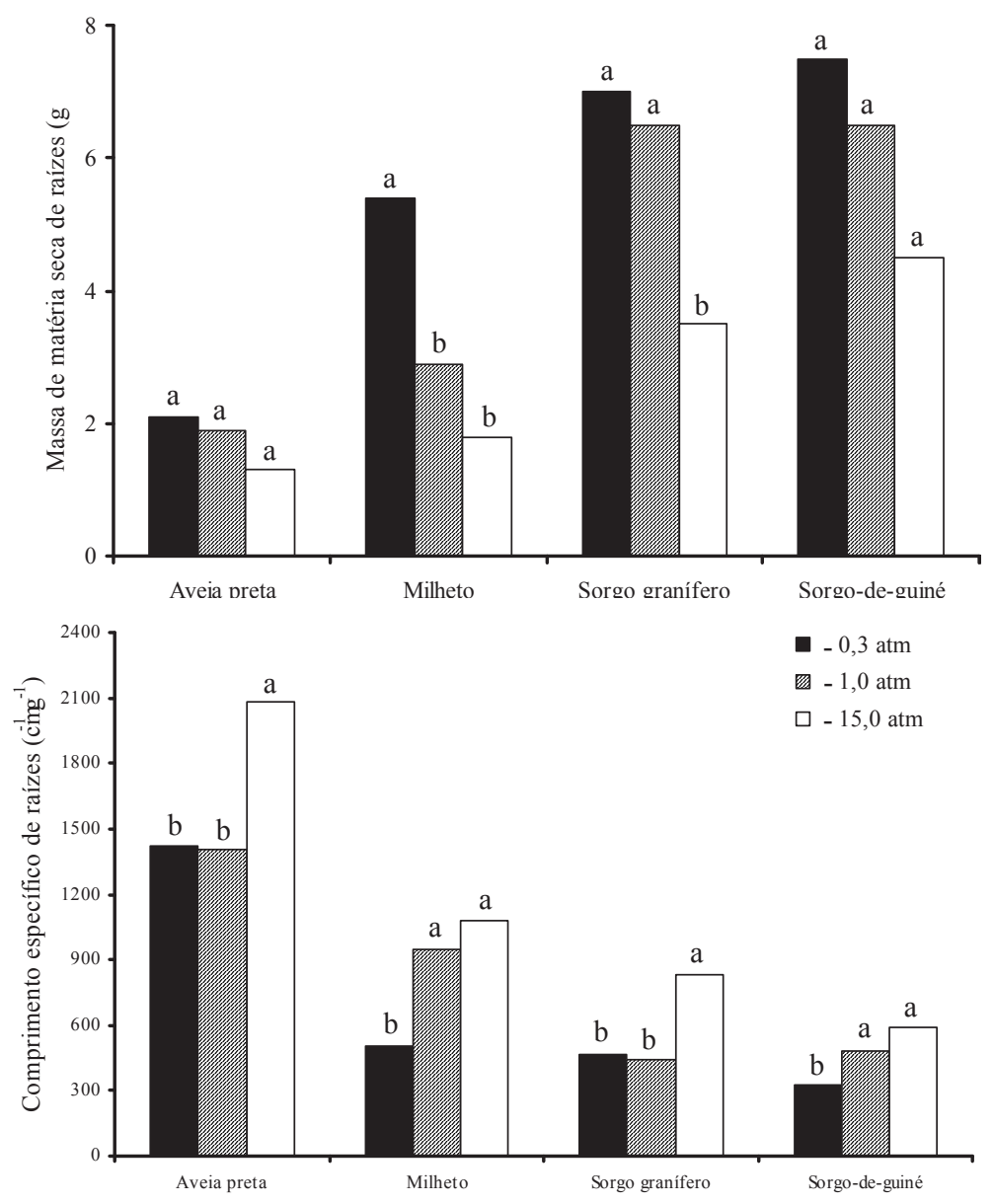

Fonte: Elaboração dos autores.

Quando se analisa o comprimento de cada uma das principais classes de diâmetro das raízes (Tabela 1), nota-se que em nenhuma delas a aveia preta foi afetada pelos potenciais de água no solo, reforçando a hipótese de que a mesma apresenta alta tolerância ao déficit hídrico. O milheto por sua vez apresentou grande redução na emissão de raízes intermediárias $(0,2<\varnothing>1,8 \mathrm{~mm})$ quando cultivado com severa restrição hídrica, o que acarretou em redução do comprimento radicular total (Tabela 1). O sorgo-deguiné apresentou maior comprimento radicular total e de raízes com diâmetro entre 0,2 e 1,0 mm quando cultivado em solo com potencial hídrico de $-1,0$, resultado este que parece não ter afetado os demais resultados do sorgo-de-guiné. O sorgo granífero apresentou menor comprimento de raízes com 
diâmetro superior a $1,0 \mathrm{~mm}$ e menor comprimento radicular total nos potenciais de água de $-1,0$ atm e $-15,0$ atm (Tabela 1), potencias estes nos quais foram encontradas as maiores quantidades de raízes finas $(\varnothing<0,2 \mathrm{~mm})$, o que pode indiciar um mecanismo de adaptação do sorgo granífero a condições de baixa disponibilidade hídrica.

Tabela 1. Comprimento radicular total e das principais classes de diâmetro de aveia preta, milheto, sorgo granífero e sorgo-de-guiné sob potenciais de água no solo de $-0,3,-1,0$ e $-15,0$ atm. Botucatu - SP.

\begin{tabular}{|c|c|c|c|c|c|c|}
\hline \multirow[b]{2}{*}{$\begin{array}{l}\text { Potencial de } \\
\text { água no solo }\end{array}$} & \multirow[b]{2}{*}{$\begin{array}{l}\text { Espécie de } \\
\text { cobertura }\end{array}$} & \multicolumn{5}{|c|}{ Comprimento radicular } \\
\hline & & $\varnothing<0,2 \mathrm{~mm}$ & $\begin{array}{c}0,2>\varnothing \\
<1,0 \mathrm{~mm}\end{array}$ & $\begin{array}{c}1,0>\varnothing \\
<1,8 \mathrm{~mm} \\
\end{array}$ & $\varnothing>1,8 \mathrm{~mm}$ & Total \\
\hline $\begin{array}{l}-0,3 \mathrm{~atm} \\
-1,0 \mathrm{~atm} \\
-15,0 \mathrm{~atm}\end{array}$ & Aveia preta & $\begin{array}{l}558 \mathrm{a} \\
430 \mathrm{a} \\
471 \mathrm{a}\end{array}$ & $\begin{array}{l}1853 \mathrm{a} \\
1718 \mathrm{a} \\
1768 \mathrm{a}\end{array}$ & $\begin{array}{r}189 \mathrm{a} \\
172 \mathrm{a} \\
156 \mathrm{a}\end{array}$ & $\begin{array}{l}378 \mathrm{a} \\
344 \mathrm{a} \\
312 \mathrm{a}\end{array}$ & $\begin{array}{l}2978 \text { a } \\
2664 \text { a } \\
2707 \mathrm{a}\end{array}$ \\
\hline $\begin{array}{l}-0,3 \mathrm{~atm} \\
-1,0 \mathrm{~atm} \\
-15,0 \mathrm{~atm}\end{array}$ & Milheto & $\begin{array}{l}449 \mathrm{a} \\
414 \mathrm{a} \\
308 \mathrm{a}\end{array}$ & $\begin{array}{l}1679 \mathrm{a} \\
1798 \mathrm{a} \\
1259 \mathrm{~b}\end{array}$ & $\begin{array}{c}--\mathrm{cm}------ \\
228 \mathrm{a} \\
208 \mathrm{a} \\
124 \mathrm{~b}\end{array}$ & $\begin{array}{l}361 \mathrm{a} \\
327 \mathrm{a} \\
248 \mathrm{a}\end{array}$ & $\begin{array}{l}2717 \mathrm{a} \\
2747 \mathrm{a} \\
1939 \mathrm{~b}\end{array}$ \\
\hline $\begin{array}{l}-0,3 \mathrm{~atm} \\
-1,0 \mathrm{~atm} \\
-15,0 \mathrm{~atm}\end{array}$ & $\begin{array}{l}\text { Sorgo } \\
\text { granífero }\end{array}$ & $\begin{array}{c}450 \mathrm{~b} \\
479 \mathrm{ab} \\
651 \mathrm{a}\end{array}$ & $\begin{array}{l}2078 \mathrm{a} \\
2077 \mathrm{a} \\
1791 \mathrm{a}\end{array}$ & $\begin{array}{c}-\mathrm{cm}----- \\
246 \mathrm{a} \\
186 \mathrm{~b} \\
155 \mathrm{~b}\end{array}$ & $\begin{array}{l}491 \mathrm{a} \\
125 \mathrm{c} \\
310 \mathrm{~b}\end{array}$ & $\begin{array}{l}3265 \mathrm{a} \\
2867 \mathrm{~b} \\
2907 \mathrm{~b}\end{array}$ \\
\hline $\begin{array}{c}-0,3 \mathrm{~atm} \\
-1,0 \mathrm{~atm} \\
-15,0 \mathrm{~atm}\end{array}$ & $\begin{array}{l}\text { Sorgo-de- } \\
\text { guiné }\end{array}$ & $\begin{array}{l}323 \mathrm{a} \\
482 \mathrm{a} \\
384 \mathrm{a}\end{array}$ & $\begin{array}{c}1480 \mathrm{~b} \\
1869 \mathrm{a} \\
1619 \mathrm{ab}\end{array}$ & $\begin{array}{c}-\mathrm{cm}---- \\
221 \mathrm{a} \\
258 \mathrm{a} \\
251 \mathrm{a}\end{array}$ & $\begin{array}{l}442 \mathrm{a} \\
515 \mathrm{a} \\
396 \mathrm{a}\end{array}$ & $\begin{array}{l}2466 \mathrm{~b} \\
3124 \mathrm{a} \\
2650 \mathrm{~b}\end{array}$ \\
\hline
\end{tabular}

Médias seguidas da mesma letra na coluna e, para cada espécie, não diferem entre si pele teste de Tukey a 5\% de probabilidade.

Fonte: Elaboração dos autores.

De igual modo ao ocorrido para a massa de matéria seca de raízes, o maior comprimento radicular total, independentemente do potencial de água no solo, foi apresentado pelo sorgo granífero ou pelo sorgode-guiné (Tabela 2). Com o solo na capacidade de campo e no ponto de murcha permanente o maior comprimento radicular total foi do sorgo granífero, enquanto o sorgo-de-guiné destacou-se com o potencial hídrico de $-1,0 \mathrm{~atm}$ (Tabela 2). Tal fato provavelmente esteja associado ao mecanismo de tolerância à deficiência hídrica, já constatado para o sorgo granífero (NOUR; WEIBEL, 1978; SINGH; SINGH, 1995). O milheto por sua vez apresentou o menor comprimento radicular total quando da menor disponibilidade de água no solo (Tabela 2), reforçando a hipótese de que é mais sensível ao déficit hídrico do que as demais espécies estudadas.
Analisando-se conjuntamente os resultados pode-se concluir que, em regiões de inverno seco, o milheto, o sorgo granífero e o sorgo-de-guiné são boas opções para a produção de matéria seca na entressafra. O sorgo granífero e o sorgo-de-guiné por apresentarem abundante sistema radicular (o que confere aos mesmos certa tolerância a condições de baixa disponibilidade hídrica), e o milheto, por apresentar elevado potencial produtivo de matéria seca, mesmo sendo mais sensível ao déficit hídrico. A aveia preta, mesmo apresentando aparentemente elevada tolerância à deficiência hídrica (tolerância esta conferida pela maior porcentagem de raízes finas), parece ser muito prejudicada por temperaturas mais elevadas, comuns nestas regiões. 


\section{Referências}

AVELAR, B. C.; MORAIS, A. R. Influência das épocas de plantio na cultura do sorgo granífero em solo de cerrado. Pesquisa Agropecuária Brasileira, Brasília, v. 21, n. 10, p. 1055-1065, 1986.

BAYER, C.; MIELNICZUK, J. Características químicas do solo afetadas por métodos de preparo e sistemas de cultura. Revista Brasileira de Ciência do Solo, Viçosa, v. 21, n. 1, p. 105-112, 1997.

BELLIDO, L. L. Cultivos herbáceos: cereales. Madrid: Mundi-Prensa, 1990. 539 p.

BUCCI, S. J.; GOLDSTEIN, G.; MEINZER, F. C.; SCHOLZ, F. G.; FRANCO, A. C.; BUSTAMANTE, M. Functional convergence in hydraulic architecture and water relations of tropical savanna trees: from leaf to whole plant. Tree Physiology, Victoria, v. 24, n. 8, p. 891-899, 2004.

CASTOLDI, G.; COSTA, M. S. S. M.; COSTA, L. A. M.; PIVETTA, L. A.; STEINER, F. Sistemas de cultivo e uso de diferentes adubos na produção de silagem e grãos de milho. Acta Scientiarum. Agronomy, Maringá, v. 33, n. 1, p. 139-146, 2011.

CRUSCIOL, C. A. C.; SORATTO, R. P. Nitrogen supply for cover crops and effects on peanut grown in sucession under a no-till system. Agronomy Journal, Madison, v. 101, n. 1, p. 41-46, 2009.

DEBARBA, L.; AMADO, T. J. C. Desenvolvimento de sistemas de produção de milho no Sul do Brasil com características de sustentabilidade. Revista Brasileira de Ciência do Solo, Viçosa, v. 21, n. 3, p. 473-480, 1997.

DERPSCH, R.; CALEGARI, A. Plantas para adubação verde de inverno. Londrina: IAPAR, 1992.80 p. (Circular IAPAR, 73).

EMPRESA BRASILEIRA DE PESQUISA AGROPECUÁRIA - EMBRAPA. Centro Nacional de Pesquisa de Solos. Manual de métodos de análises de solos. 2. ed. Rio de Janeiro: Embrapa-CNPS, 1997. 212 p.

FERNÁNDEZ, C. J.; McINNES, K. J.; COTHREN, J. T. Water status and leaf area production in water-and nitrogen-stressed cotton. Crop Science, Madison, v. 36, n. 5, p. 1224-1233, 1996.

FLARESSO, J. A.; GROSS, C. D.; ALMEIDA, E. X. Época e densidade de semeadura de aveia preta (Avena strigosa Schreb.) e Azevém (Lolium multiflorum Lam.) no Alto Vale do Itajaí, Santa Catarina. Revista Brasileira de Zootecnia, Viçosa, v. 30, n. 6, p. 1969-1974, 2001.
FRANCO, A. C.; BUSTAMANTE, M.; CALDAS, L. S.; GOLDSTEIN, G.; MEINZER, F. C.; KOZOVITS, A. R.; RUNDEL, P.; CORADIN, V. T. R. Leaf functional traits of Neotropical savanna trees in relation to seasonal water deficit. Trees, Berlin, v. 19, n. 3, p. 326-335, 2005.

GONÇALVES, W. G.; JIMENEZ, R. L.; ARAÚJO FILHO, J. V.; ASSIS, R. L.; SILVA, G. P.; PIRES, F. R. Sistema radicular de plantas de cobertura sob compactação do solo. Engenharia Agrícola, Jaboticabal, v. 26, n. 1, p. 67-75, 2006.

HOOGENBOOM, G.; HUCK, M. G.; PETERSON, C. M. Root growth rate of soybean as affected by drought stress. Agronomy Journal, Madison, v. 79, n. 4, p. 607614, 1987.

JOSHI, N. L. Seedling emergence and yield of pearl millet on naturally crusted arid soils in relation to sowing and cultural methods. Soil and Tillage Research, Amsterdam, v. 10, n. 2, p. 103-112, 1987.

LEMOS, L. B.; NAKAGAWA, J.; CRUSCIOL, C. A. C.; CHIGNOLI JÚNIOR, W.; SILVA, T. R. B. Influência da época de semeadura e do manejo da parte aérea de milheto sobre a soja em sucessão em plantio direto. Bragantia, Campinas, v. 62, n. 3, p. 405-415, 2003.

LILJENBERG, C.; KARUNEN, P.; EKMAN, R. Changes in steryl lipids of oat avena-sativa cultivar seger root cells as a function of water-deficit stress. Physiologia Plantarum, Copenhagen, v. 63, n. 3, p. 253-257, 1985.

LIRA, M. A.; MACIEL, G. A.; TABOSA, J. N.; ALVES, M. R.; SANTOS, J. PO.; FREITAS, E. V.; ARCOVERDE, A. S. Cultivo do milheto (Pennisetum americanum (L.) Leeke). Recife: IPA, 1983. 6 p. (Instruções técnicas, 8).

MAGALHÃES, P. C.; DURAES, F. O. M.; SCHAFFERT, R. E. Fisiologia da planta de sorgo. Sete Lagoas: Embrapa-CNPMS, 2000. 46 p. (Circular técnica, 3).

MATEUS, G. P.; BORGHI, E.; CASTRO, G. S. A.; GARCIA, R. A.; CRUSCIOL, C. A. C. Produção de fitomassa e acúmulo de nutrientes na parte aérea do sorgo de Guiné gigante. Revista Ciência Agronômica, Fortaleza, v. 42, n. 4, p. 1000-1008, 2011.

MATEUS, G. P.; CRUSCIOL, C. A. C.; NEGRISOLI, E. Palhada do sorgo de guiné gigante no estabelecimento de plantas daninhas em área de plantio direto. Pesquisa Agropecuária Brasileira, Brasília, v. 39, n. 6, p. 539-542, 2004.

McCREE, K. J.; FERNÁNDEZ, C. J. Simulation model for studying physiological water stress responses of whole plants. Crop Science, Madison, v. 29, n. 2, p. 353360, 1989. 
NOUR, A. M.; WEIBEL, D. E. Evaluation of root characteristics in grain sorghum. Agronomy Journal, Madison, v. 70, n. 2, p. 217-218, 1978.

NOZAKI, M. H.; VENDRÚSCULO, M. Características químicas e densidade global de um latossolo vermelho eutróferrico cultivado com plantas de cobertura em Toledo-PR. Semina: Ciências Agrárias, Londrina, v. 31, p. 1245-1252, 2010. Suplemento 1.

PAUL, C. L. El uso de água y nutrientes por la planta de sorgo. In: _. Agronomia del sorgo. Hydebarad: Índia, 1990. p. $151-208$.

PIMENTEL, C. A relação da água com a planta. Seropédica: Edur, 2004. 191 p.

PONTES, M. J. S. F. Avaliação de genótipos de sorgo (Sorghum bicolor (L.) Moench) em comparação com genótipos de milho (Zea mays L.) e de milheto (Pennisetum americanum (L.) R. BR.) visando tolerância ao estresse hídrico no estádio de plântula. 1997. Dissertação (Mestrado em Fisiologia e Biotecnologia) Universidade Federal Rural de Pernambuco, Recife.

POORTER, H.; GARNIER, E. The ecological significance of variation in relative growth rate and its components. In: PUGNAIRE, F. I.; VALLADARES, F. (Ed.). Handbook of functional plant ecology. New York: Marcel Dekker, Inc., 1999. p. 81-120.

PORTUGAL, A. F.; ROCHA, V. S.; SILVA, A. G.; PINTO, G. H. F.; PINA-FILHO, O. C. Fenologia de cultivares de sorgo no período de verão e rebrota na safrinha. Revista Ceres, Viçosa, v. 50, n. 289, p. 325-336, 2003.

PÖTKER, D.; ROMAN, E. S. Efeito de resíduos de culturas e do pousio de inverno sobre a resposta do milho a nitrogênio. Pesquisa Agropecuária Brasileira, Brasília, v. 29, n. 5, p. 763-770, 1994.

RAIJ, B. V.; CANTARELlA, H.; QUAGGIO, J. A.; FURLANI, A. M. C. Recomendações de adubação e calagem para o Estado de São Paulo. 2. ed. Campinas: Instituto Agronômico \& Fundação IAC, 1997. 285 p. (Boletim técnico, 100).
RAIJ, B. V.; QUAGGIO, A. J. Métodos de análise do solo para fins de fertilidade. Campinas: Instituto Agronômico, 1983. 31 p. (Boletim técnico, 81).

ROSOlEM, C. A.; PACE, L.; CRUSCIOL, C. A. C. Nitrogen management in maize cover crop rotations. Plant and Soil, Dordrecht, v. 264, n. 1-2, p. 261-271, 2004.

SANTOS, H. G. dos; JACOMINE, P. K. T.; ANJOS, L. H. C. dos; OLIVEIRA, V. A. de OLIVEIRA, J. B. de; COELHO, M. R.; LUMBRERAS, J. F.; CUNHA, T. J. F. (Ed.). Sistema brasileiro de classificação de solos. 2. ed. Rio de Janeiro: Embrapa Solos, 2006. 306 p.

SANTOS, R. F.; CARLESSO, R. Déficit hídrico e os processos morfológico e fisiológico das plantas. Revista Brasileira de Engenharia Agrícola e Ambiental, Campina Grande, v. 2, n. 3, p. 287-294, 1998.

SEIFFERT, N. F.; BARRETO, I. L. Forrageiras para ensilagem. I. Avaliação de cultivares de milho (Zea mays L.), sorgo (Sorgnun sp.) e milheto ( Pennisetum americanum Schum.) na região da Depressão Central do Rio Grande do Sul. Agronomia Sulriograndense, Porto Alegre, v. 13, n. 1, p. 205-214, 1977.

SINGH, B. R.; SINGH, D. P. Agronomic and physiological responses of sorghum, maize and pearl millet to irrigation. Field Crops Research, Amsterdam, v. 42, n. 2-3, p. 57-67, 1995.

SKERMAN, P. J.; RIVEROS, F. Gramíneas tropicales. ROMA: FAO, 1992. 849 p. (Coleción FAO: Producción y protección vegetal, 23).

WONG, J. Nutrição e adubação do sorgo granífero. In: BRINHOLI, O. Cultura do sorgo granífero (Sorghum bicolor L.). Botucatu: Faculdade de Ciências Agronômicas/UNESP, 1996. p. 49-66. 